\title{
Effect of Critical Micelle Concentration of Sodium Dodecyl Sulfate Dissolved in Calcium and Carbonate Source Solutions on Characteristics of Calcium Carbonate Crystals
}

\author{
Jun-Hwan Bang ${ }^{1}$, Kyung Sun Song ${ }^{1}$, Myung Gyu Lee ${ }^{2}$, Chi Wan Jeon ${ }^{1}$ and Young Nam Jang ${ }^{1, *}$ \\ ${ }^{1}$ Geologic Environment Division, Korea Institute of Geoscience and Mineral Resources (KIGAM), \\ Gwahang-no 92, Yuseong-gu, Daejeon, 305-350, Korea \\ ${ }^{2}$ Resources Recycling Engineering Department, University of Science and Technology of Korea, \\ Gwahang-no 113, Yuseong-gu, Daejeon, 305-333, Korea
}

\begin{abstract}
Various concentrations of anionic surfactant, sodium dodecyl sulfate (SDS), were used to control the growth of calcium carbonate crystals. The obtained calcium carbonate particles were characterized by Fourier transform infrared spectrometry (FT-IR), X-ray diffraction (XRD), field emission-scanning electron microscopy (FE-SEM), laser scattering particle size analyzer and zeta potential analyzer techniques. The effect of various concentrations including critical micelle concentration (CMC) in calcium and carbonate source solutions on the polymorph, morphology, particle size distribution and zeta potential of the particles were studied. It was demonstrated that varied SDS concentrations in carbonate source solution has obvious effect on the characteristics of calcium carbonate particles, while varied SDS concentration in calcium source solution does not affect the characteristics. Also, it was observed that SDS affected orientation development of calcium carbonate crystals. [doi:10.2320/matertrans.M2010134]
\end{abstract}

(Received April 16, 2010; Accepted May 31, 2010; Published July 14, 2010)

Keywords: calcium carbonate, sodium dodecyl sulfate (SDS), critical micelle concentration (CMC), polymorph, morphology

\section{Introduction}

Inorganic materials such as calcium carbonate, gypsum and portlandite are very useful for construction, medicine, cosmetics, etc. ${ }^{1,2)}$ The physical properties like controlled morphology, polymorph and size may enhance their usefulness. The synthetic methods have been developed with using organic molecules such as polymers and/or surfactants to control the characteristics of inorganic materials. PEG (polyethylene glycol) and SDS (sodium dodecyl sulfate) offered templates for crystallization of calcium carbonate resulted in hollow sphere crystals. ${ }^{3)}$ Polymorph is affected by varied concentrations of PEG and SDS, respectively. Zhang et $a l^{4)}$ reported the acts of anionic, cationic and nonionic surfactants on the morphology of calcium carbonate under high pressure. Three types of surfactants produced calcite only but their morphologies were seems to be dissimilar. Nonionic surfactant, Tween 80 , brought plate-like crystals shows with inhibited growth of particular crystal faces. Cationic surfactant, CTAB, resulted in typical rhombohedron calcium carbonate without considerable effectiveness in morphological transformation. Similar kind of results has also been reported by $\mathrm{Yu}$ et al. ${ }^{5)}$ In presence of anionic surfactant, SDS, roughly surfaced cubic calcium carbonate was obtained. The negatively charged hydrophilic groups of anionic surfactant tends to drive a high supersaturation of cations locally, which isolates the cations among the anionic ion groups owing to the formation of micells.

Different effects of other anionic surfactants on crystallization of calcium carbonate were investigated. SDBS (sodium dodecylbenzenesulfonate) involved in polymorphic alteration of calcium carbonate (calcite to vaterite) within the

*Corresponding author, E-mail: jhbang@kigam.re.kr range of 0.5 to $5 \mathrm{mM}$ concentration. Morphological transformation of rhombohedron to sphere was achieved additionally. The benzene ring connected to sulfonate group changed spatial location of head groups of SDBS at the interface of surfactant/nuclei, and which may cause alteration to vaterite. ${ }^{6}$ High SDS concentration significantly affected on variation of crystal morphology and polymorph of synthesized calcium carbonate. The high concentration of SDS $(0.25 \mathrm{M})$ vanished away the calcite and thus resulted in only vaterite with olive like shape and at the same time the lowest concentration $(0.05 \mathrm{M})$ of SDS built rod shape type calcite. Coexistence of spherical calcite and vaterite was also induced from $0.1 \mathrm{M}$ of SDS. ${ }^{7)}$ The role of SDS was made in crystallization that is the interactions between surfactant and crystal face of calcium carbonate after nuclei formed. ${ }^{8)}$ As a result, there is an aggregation of nano sized flower shape calcite and aragonite. It is easy to find the works in which only carbonate source solution contains surfactants for the crystallization of calcium carbonate. However, the present investigation basically considers the isolation of calcium ion by addition of SDS with varied concentrations. We also care CMCs (critical micelle concentrations) of SDS in both solutions of $0.5 \mathrm{M}$ calcium source and carbonate source that could affect on size, morphology and/or polymorph of synthesized calcium carbonate.

\section{Experiments}

\subsection{Materials and experimental procedures}

The $0.5 \mathrm{M}$ concentration of calcium was prepared from calcium chloride dehydrate $\left(\mathrm{CaCl}_{2} \cdot 2 \mathrm{H}_{2} \mathrm{O}\right.$, Junsei Chemical, $99 \%$ ). In similar way the $0.5 \mathrm{M}$ of the carbonate ion was prepared from sodium carbonate $\left(\mathrm{Na}_{2} \mathrm{CO}_{3}\right.$, Kanto Chemical, $99 \%$ ). These two reagents are widely used as the sources of 
Table 1 Concentrations of SDS in each source solution and their combinations

\begin{tabular}{|c|c|c|c|}
\hline & Combinations & $\begin{array}{l}\text { SDS concentrations } \\
\text { in } 0.5 \mathrm{M} \text { of } \mathrm{Ca}^{2+} \\
\text { source solution } \\
(/ \mathrm{mM})^{* 1}\end{array}$ & $\begin{array}{c}\text { SDS concentrations } \\
\text { in } 0.5 \mathrm{M} \text { of } \mathrm{CO}_{3}{ }^{2-} \\
\text { source solution } \\
(/ \mathrm{mM})^{* 1}\end{array}$ \\
\hline \multirow{6}{*}{ Symbols } & $(a+w)$ & $a$ (none) & $w$ (none) \\
\hline & $(a+y)$ & $b(0.10)$ & $x(0.10)$ \\
\hline & $(b+x)$ & $c(0.79)^{* 2}$ & $y(0.88)^{* 2}$ \\
\hline & $(c+w)$ & $d(10.0)$ & $z(10.0)$ \\
\hline & $(c+y)$ & & \\
\hline & $(d+z)$ & & \\
\hline
\end{tabular}

${ }^{* 1}$ each volume of individual solution is $50 \mathrm{~mL}$.

*2 expresses CMCs of SDS in $0.5 \mathrm{M}$ of $\mathrm{CaCl}_{2} \cdot 2 \mathrm{H}_{2} \mathrm{O}$ and $\mathrm{Na}_{2} \mathrm{CO}_{3}$ at $293 \mathrm{~K}$, respectively.

calcium and carbonate ions with liquid phase for crystallization of calcium carbonate. SDS (Sigma-Aldrich, 99\%) was used as anionic surfactant. CMCs of SDS in both solutions were $0.79 \mathrm{mM}$ and $0.88 \mathrm{mM}$ for calcium and carbonate source $(0.5 \mathrm{M}$ each $)$ solutions, respectively. Table 1 shows that various concentration of SDS in each source solution, and provides the information of their combinations. All the experimental studies were performed at an ambient temperature. White agglomeration was formed immediately as calcium source solutions took SDS and the agglomeration was deep as SDS concentration increased. Ultrasonic and vigorous stirring over than $20 \mathrm{~min}$ allowed calcium source solutions which would keep homogeneity with broken clusters until $50 \mathrm{~mL}$ of that was taken off. Rapid pouring of same volume of carbonate source solutions was followed without agitation.

Precipitations in the all combined solutions were aged at $296 \mathrm{~K}$ for $20 \mathrm{~h}$, then filtered with $0.2 \mu \mathrm{m}$ mixed cellulose ester membrane (Advantec). Cold ethanol rinsed particles several times, and ethanol was vaporized at $303 \mathrm{~K}$. All aqueous solutions were made of Milli-Q water.

\subsection{Characterization}

The polymorph of synthesized calcium carbonate particles was characterized and identified by powder XRD (Analytical X-ray B.V. X'pert-MPD, Philips). FT-IR (NICOLET 380, Thermo Fisher Scientific Inc.) spectral study is again evidenced on the polymorph structure as well as the probability of SDS remaining on particles. FE-SEM (S4700, HITACHI) was used to study in order to see the morphologies of the magnified particles. Particle size distribution was measured by laser scattering particle size analyzer (Sympatec GmbH, HELOS/RODOS \& SUCELL). In addition to that the zeta potential of the respective samples was also measured (Otsuka Electronics, ELS-8000).

\section{Results and Discussion}

Figure 1 shows FT-IR spectra of the typical calcium carbonate crystals synthesized at various concentrations of SDS in calcium and carbonate source solutions. The transmittance peaks at $\left.712 \mathrm{~cm}^{-1}, 9\right) \quad 877 \mathrm{~cm}^{-110)}$ and $1430 \mathrm{~cm}^{-1},{ }^{11)}$ corresponds to the transmittance of due to the presence of compounds namely calcite and vaterite and

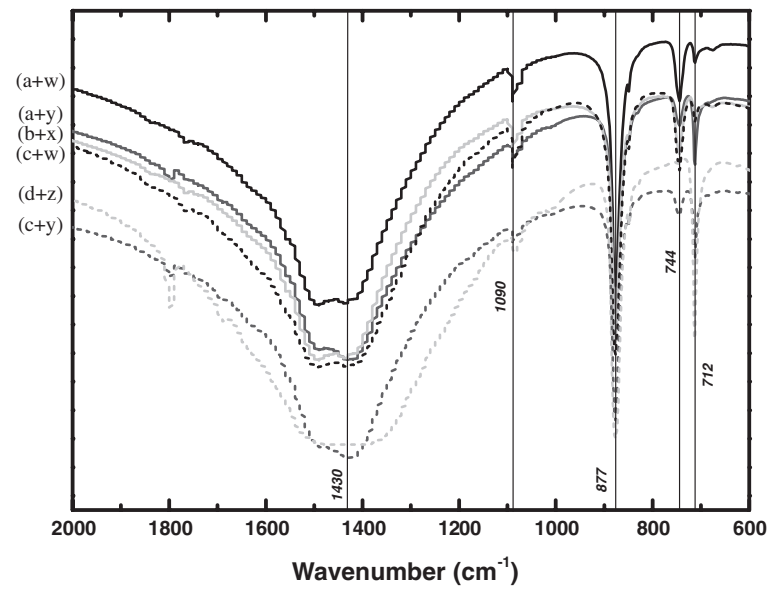

Fig. 1 Transmittance of infrared spectra of synthesized calcium carbonate from combination of solutions according to Table 1 . Calcite $\left(712 \mathrm{~cm}^{-1}\right.$, $877 \mathrm{~cm}^{-1}$ and $\left.1430 \mathrm{~cm}^{-1}\right)$, vaterite $\left(744 \mathrm{~cm}^{-1}\right)$ were coexisted and aragonite $\left(1090 \mathrm{~cm}^{-1}\right)$ was present with question. SDS was not remained on the crystal surfaces.

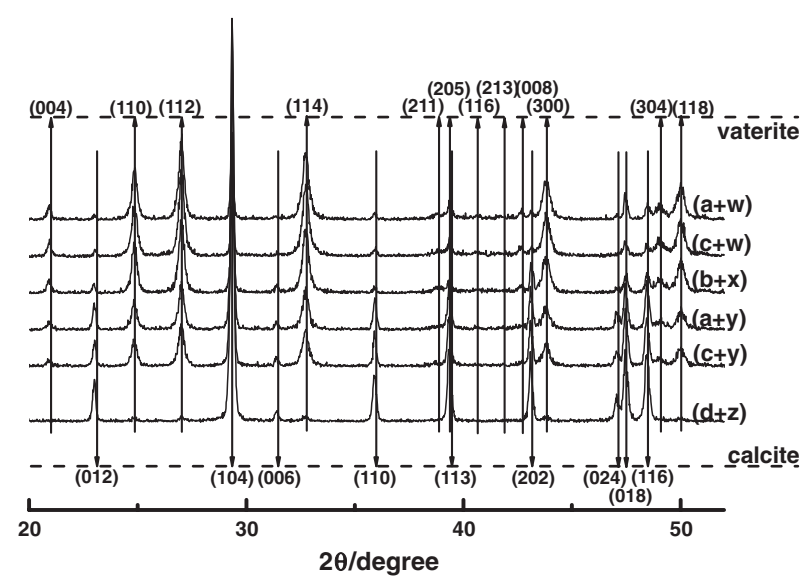

Fig. 2 X-ray diffraction patterns of calcium carbonate from combined solutions according to Table 1. Despite from the FT-IR results, X-ray diffraction patterns reveal that synthesized calcium carbonate did not include aragonite. As concentration of SDS increases in carbonate source solutions, calcite predominantly formed. SDS in calcium source solutions did not affect alteration of polymorph.

in the similar way the peak at $744 \mathrm{~cm}^{-1}$ also evident the coexistence of vaterite. ${ }^{9)}$ A small peak at $1090 \mathrm{~cm}^{-1}$ was suspected the presence of aragonite. ${ }^{8)}$ Any peak of SDS was not found among these spectra. ${ }^{12)}$ Cold ethanol was effective enough to remove surfactant on particle surfaces.

X-ray diffraction patterns, as shown in Fig. 2 identify that polymorph of calcium carbonate from combinations of source solutions; calcite from $(d+z)$, dominant vaterite with little calcite from $(a+w),(c+w)$ and $(b+x)$ and dominant calcite with little vaterite from $(a+y)$ and $(c+y)$. Although the small FT-IR peak at $1090 \mathrm{~cm}^{-1}$ questionably suggested due to the presence of aragonite but from the $\mathrm{X}$-ray diffraction pattern, aragonite was not found. There is small shift of the transmittance peak from 1099 to $1090 \mathrm{~cm}^{-1}$ which corresponds to the spectra due to the presence of calcite. ${ }^{13)}$ In accordance with FT-IR transmittance spectra and X-ray diffraction patterns, aragonite was not formed. $3,6,7,9,11,14$ ) 
SDS in carbonate source solutions (not in calcium source solutions) caused polymorphic alteration of calcium carbonate. The combined solutions, $(a+w)$ and $(c+w)$, had common solution i.e. $w$ in which SDS was not dissolved and these two combined solutions produced mainly vaterite. The solution of $x$ in which SDS was dissolved lower than CMC also contributed to produce vaterite mainly. With increase in the SDS concentration through CMC in carbonate source solutions, exerted polymorphic alteration (vaterite to calcite) and especially when SDS concentration met to CMC level, the calcite type was turned to be dominant polymorph. CMC in carbonate source solution served as critical point of polymorphic alteration. Interestingly at the circumstance like in absence of SDS, crystals grew as vaterite easily without concerning isolation or liberation of calcium ions by SDS micelles. According to combined solutions of $(a+w)$ and $(a+y)$, while changing the concentration of SDS in calcium source solution, it did not affect on calcite and/or vaterite formations. Polymorph of calcium carbonate is controlled by the solution environment of that carbonate ions present. Negatively charged head groups of anionic surfactant provide enough electrons to the surface of nuclei of amorphous calcium carbonate, and this would develop vaterite to calcite. ${ }^{6)}$ Therefore, it was assumed that the polymorph of synthesized calcium carbonate is a matter of supplementary SDS in carbonate source solution.

The quantity of different orientations of calcium carbonate polymorph, calcite and vaterite was estimated according to the following eq. (1): ${ }^{10)}$

$$
\% h k l=\frac{I_{\mathrm{hkl}} / I_{\mathrm{hkl}}^{*}}{\sum_{\mathrm{hkl}}\left(I_{\mathrm{hkl}} / I_{\mathrm{hkl}}^{*}\right)} \times 100
$$

where, $I_{\mathrm{hkl}}^{*}$ is standard intensities from JCPDS 05-0586 for calcite and 25-0127 for vaterite, and $I_{\mathrm{hkl}}$ represents intensities of XRD patterns of the samples.

The results obtained on calculating with using eq. (1) thus expresse the different orientational uniformity of each crystal polymorph as shown in Fig. 3. Calcite orientations had no obvious differences among the combined solutions. ${ }^{10)}$ Meanwhile vaterite had specifically developed orientation, (205), whose proportion was increased with SDS concentration in carbonate source solutions. CMC of SDS in carbonate source solution also served as critical point of orientation development of vaterite.

Table 2 shows the size distribution and zeta potential of synthesized calcium carbonate particles. It was even expected that varied concentrations of SDS would affect on size distribution as higher SDS promoted alteration of vaterite to calcite. However, $50 \%$ of accumulated size were found to be all about $8 \mu \mathrm{m}$ with narrow distribution and it is independent on SDS concentrations in both source solutions. Carbonate ions were supposed to react completely with calcium ions because zeta potential of synthesized particles from $(a+w)$ solution was positive. Zeta potential changed steeply twice when the concentration of SDS met CMC in calcium source solutions; as on combined solutions with $c$. Addition of SDS in crystallization process gave calcium carbonate particles negative potential; especially CMC of SDS in calcium source solution induced steep changes of potential negatively.
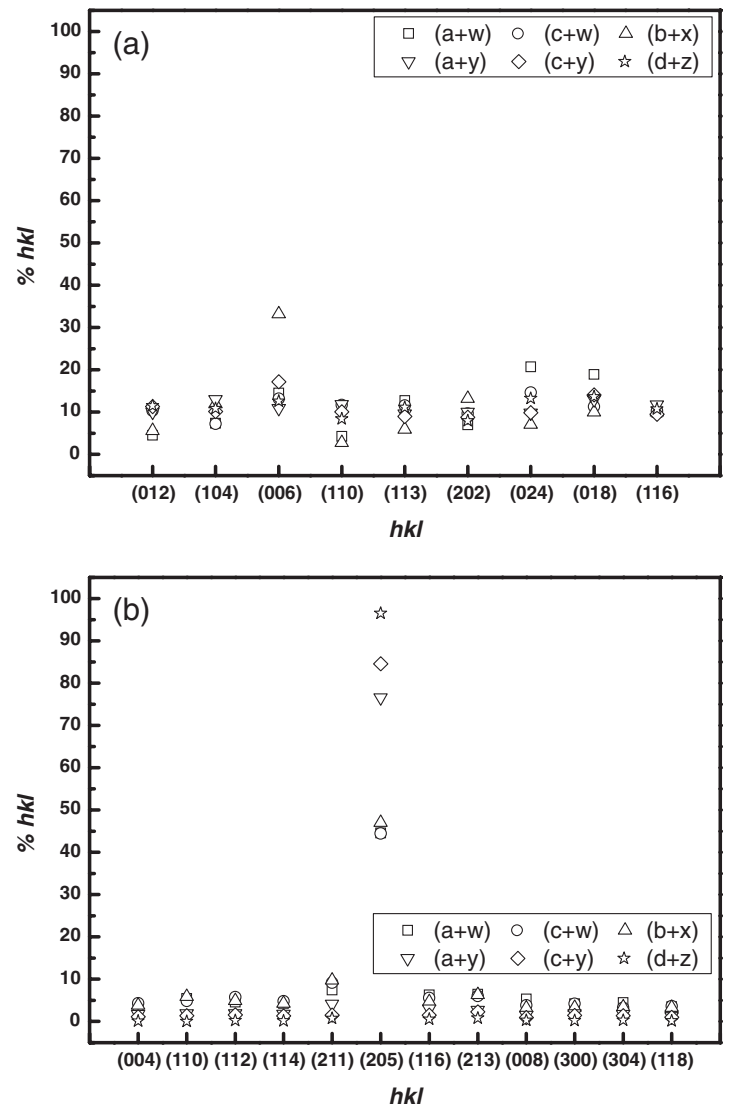

Fig. 3 The relative development of orientations ( $h k l$ ) of (a) calcite and (b) vaterite by calculating eq. (1). JCPDS 05-0586 and 25-0127 offered reference intensities of both polymorphs.

Table 2 Size distribution and zeta potential of synthesized calcium carbonate from combined solutions relevant to Table 1 .

\begin{tabular}{cccccccc}
\hline Combination of solutions & $(a+w)$ & $(c+w)$ & $(b+x)$ & $(a+y)$ & $(c+y)$ & $(d+z)$ \\
\hline Size $(\mu \mathrm{m})^{*}$ & 7.62 & 7.92 & 8.25 & 7.82 & 7.70 & 7.36 \\
\hline Zeta potential $(\mathrm{mV})$ & 3.34 & -2.06 & -2.18 & -2.91 & -6.25 & -5.54 \\
\hline$* 50 \%$ accumulated size & & & & &
\end{tabular}

Figure 4 shows the morphologies of synthesized calcium carbonate accordance with Table 1 . It is widely known that vaterite usually has "rice" like shape and whereas the synthetic calcite is of cubic in shape. The alteration of polymorph, vaterite to calcite, is obvious and which can be clearly seen on FE-SEM images and X-ray patterns. Dosed organic molecules in crystallization of calcium carbonate cause polymorphic change, like amorphous to calcite or vaterite. ${ }^{15)}$ Micells in carbonate source solution (i.e. solution y) accelerated morphological transformation namely neat sphere to roughly surfaced sphere, and polymorphic alteration; vaterite to calcite (according to XRD patterns). Combined solution $(a+y)$ produced tiny vaterite particles and relatively large cubic calcite as a medium of polymorphic and mophological alteration. Hypothesis of the role of $\mathrm{CMC}$ in carbonate source solution is as illustrated in FE-SEM images that confirmed from XRD patterns too. Another assumption has been suggested that the previously formed spherical vaterite turn to calcite with the assistance of SDS. 

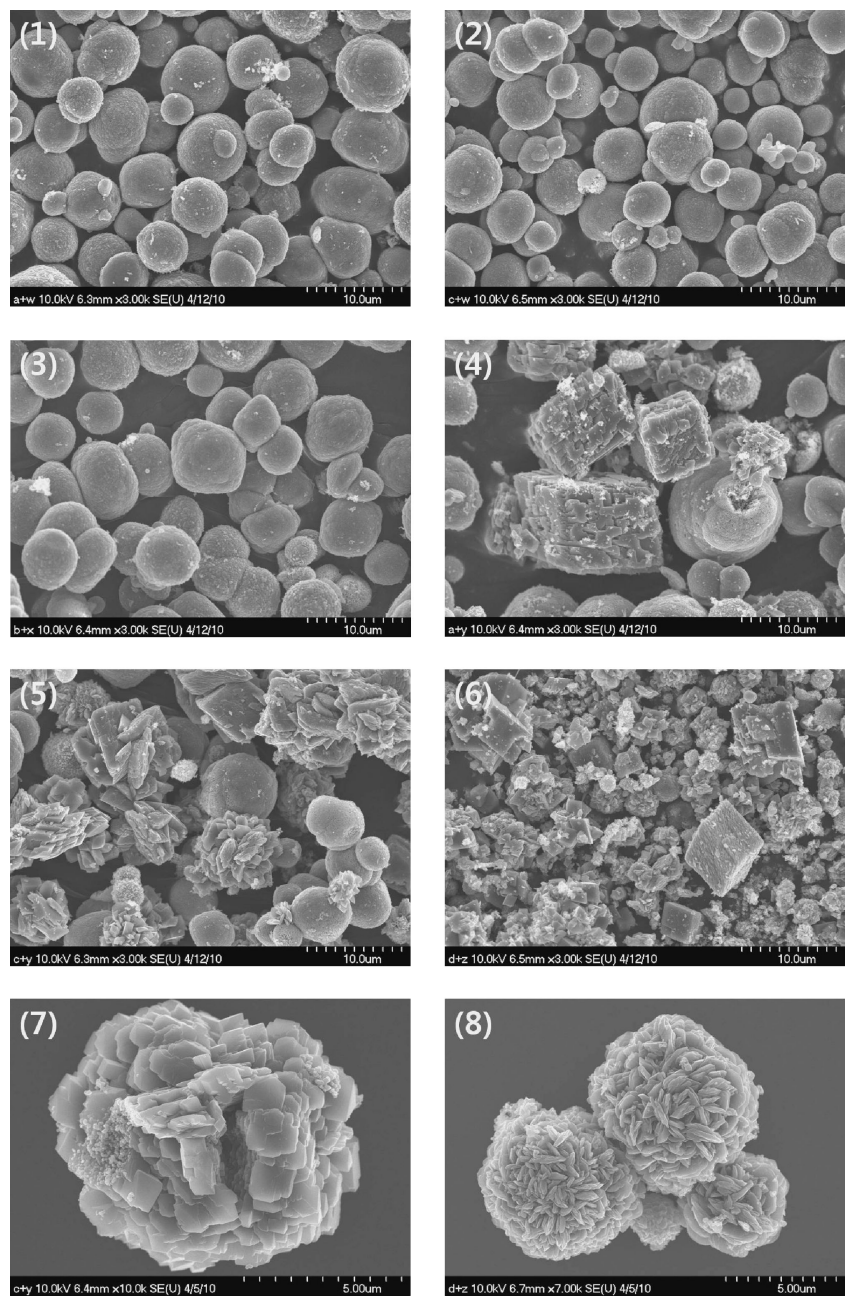

Fig. 4 FE-SEM images of synthesized calcium carbonate referred to Table 1. When concentration of SDS increases in carbonate source solution, calcite is clearly seen while tiny vaterite is disappeared. This tendency is well established through the images $(a+y),(c+y)$ and $(d+z)$. The particles shown in (1), (2), (3), (4), (5) and (6) are synthesized from the combinations of the solutions, $(a+w),(c+w),(b+x),(a+y)$, $(c+y)$ and $(d+z)$, respectively. Images of (7) and (8) are magnified images of particles from the combinations of $(c+y)$ and $(d+z)$.

\section{Conclusions}

Dissolved SDS in source solutions of calcium and carbonate ions predominantly affected on the morphology, polymorph, zeta potential and orientations of calcium carbonate, but not on size distribution. Vaterite was dominant polymorph when SDS concentration decreased in the carbonate source solutions. Alteration of vaterite to calcite was enhanced as carbonate source solution contained higher concentration of SDS than CMC. However, any of SDS concentrations in calcium source solution was not connected to polymorph alteration significantly. Orientation of vaterite was affected from CMC of SDS in carbonate source solutions, but calcite did not have significant differences in orientations. CMC of SDS in carbonate source solution introduced steep changes of zeta potential.

\section{Acknowledgment}

This research was supported by the Basic Research Project (GP 2010-018) of the Korea Institute of Geoscience and Mineral Resources (KIGAM) funded by the Ministry of Knowledge Economy of Korea.

\section{REFERENCES}

1) S. Mann and G. A. Ozin: Nature 382 (1996) 313-318.

2) H. Yang, N. Coombs and G. A. Ozin: Nature 386 (1997) 692-695.

3) X. Ji, G. Li and X. Huang: Mater. Lett. 62 (2008) 751-754.

4) C. Zhang, J. Zhang, X. Feng, W. Li, Y. Zhao and B. Han: Colloid Surface A 324 (2008) 167-170.

5) J. Yu, X. Zhao, B. Cheng and Q. Zhang: J. Solid State Chem. 178 (2005) 861-867.

6) H. Wei, Q. Shen, Y. Zhao, Y. Zhou, D. Wang and D. Xu: J. Cryst. Growth 264 (2004) 424-429.

7) Y. Tang, B. Y. Du, L. G. Li, J. Yang and Y. M. Zhang: Chinese Sci. Bull. 52 (2007) 78-83.

8) H. Wei, Q. Shen, Y. Zhao, D. Wang and D. Xu: J. Cryst. Growth 260 (2004) 545-550.

9) H. Wei, Q. Shen, Y. Zhao, Y. Zhou, D. Wang and D. Xu: J. Cryst. Growth 279 (2005) 439-446.

10) Q. Shen, H. Wei, L. Wang, Y. Zhou, Y. Zhao, Z. Zhang, D. Wang, G. Xu and D. Xu: J. Phys. Chem. B 109 (2005) 18342-18347.

11) T. Menahem and Y. Mastai: J. Cryst. Growth 310 (2008) 35523556.

12) B. Tang, X. Wang, G. Wang, C. Yu and Z. Chen: Talanta 69 (2006) $113-120$.

13) W. P. Griffith: Nature 224 (1969) 264-266.

14) J. Rudloff and H. Cölfen: Langmuir 20 (2003) 991-996.

15) H. Cölfen and S. Mann: Angew. Chem. Int. Edit. 42 (2003) 23502365 . 